\title{
A tale of two epidemics: gender differences in socio-demographic characteristics and sexual behaviors among HIV positive individuals in Mexico City
}

\author{
Sergio Bautista-Arredondo ${ }^{1}$, Edson Servan-Mori ${ }^{1 *}$, Fenella Beynon ${ }^{1}$, Andrea González ${ }^{2}$ and Patricia Volkow ${ }^{3}$
}

\begin{abstract}
Background: To date, the HIV epidemic in Mexico has been concentrated mainly among men who have sex with men, butheterosexual transmission, particularly to women, is increasingly important. This study examine gender differences in socio-demographic characteristics and risk behaviors of HIV positive individuals in Mexico City.

Methods: We analyzed data from a cross-sectional survey of 1,490 clinic patients (male:female ratio 8:1) with HIV inMexico City in 2010. We examined socio-demographic characteristics, risk behavior, and history of HIV infection.From multivariate non-linear probability (probit) models we calculated predicted probabilities by sex of several outcomes: marginalization, demographic and sexual risk behaviors.

Results: Significant differences were found between men and women. Multivariate models suggest that women had lower schooling levels; were less likely to have been employed in the past month and earn more than the minimal wage; more likely to have children, to have been sexually abused, to never have used condoms and to report having been infected by a stable partner. Additionally, women were less likely to report having a partner with a history of migration to the USA and to have engaged in transactional sex.

Conclusion: Significant differences exist between men and women with HIV in Mexico City in terms of their socioeconomicand behavioral profiles, which translate into differences in terms of exposure to HIV infection. Women face social and economic vulnerability while men tend to have riskier sexual behavior. Gender issues must be approached in prevention and treatment efforts, using diverse methods to target those most vulnerable and at risk.
\end{abstract}

Keywords: Gender inequality, Social vulnerability, Risk behavior, HIV, Mexico City

\section{Background}

In Mexico, like much of Central and South America, the HIV epidemic is defined as concentrated [1]. Nationally, prevalence is low (about $0.3 \%$ ), but ranges from 10 to $17 \%$ among men who have sex with men (MSM) and from 5 to $8 \%$ among intravenous drug users (IDUs) [1-3]. Higher than average prevalence is also seen among sex workers, transgender, transsexual and transvestite persons and prison inmates $[4,5]$. Of the

* Correspondence: eservan@insp.mx

${ }^{1}$ National Institute of Public Health, Cuernavaca, Mexico

Full list of author information is available at the end of the article
220,000 people estimated to be infected with HIV in Mexico, almost two thirds are MSM [1, 2].

However, heterosexual transmission increasingly plays an important role in the epidemic in Mexico, accounting for about $50 \%$ of new infections by 2010, compared with $10 \%$ in the early years of the epidemic [3]. Similarly, male to female mortality ratios have shifted from 12:1 before 1988 to $4.9: 1$ in 2012 [6]. Both global and local explanations have been offered for this trend, which is not unique to Mexico. Among them, the Pan-American Health Organization (PAHO) concluded that women are more vulnerable to infection, both biologically and socially, while men tend to be at a greater risk due to "pro-active" behavior [7]. 
Women in Mexico are vulnerable to HIV infection mainly as a result of unprotected sex with stable partners, who are at risk through unprotected sex with multiple or high risk partners, particularly other men [8-10]. Migration also plays a role in the epidemic, primarily through young men migrating to the U.S. This type of migration is linked with adopting more risky behaviors, social isolation and seeking comfort in new sexual partners [11, 12], which has implications for partners at home - most of them women. When men return home, after unprotected sex with casual partners in the U.S., condom use with their partners is very low [13-15].

Intimate partner violence (IPV) is also an important factor in the spread of HIV to women in stable relationships, by reducing women's ability to negotiate condom use and also by increased transmission risk from sexual IPV [16-19]. In Mexico, $47.1 \%$ of women have experienced some form of IPV, of which $29.9 \%$ was physical or sexual [20].

In Latin America, high HIV prevalence among MSM, combined with low risk perception and poor availability of information and access to preventive services due to stigma, lead to increased risk [21]. Despite some evidence of more consistent condom use among MSM [22-24], greater risk has been attributed to increased partner concurrency, longer periods of new partner acquisition and greater age variation in partnerships [25]. Bisexual and non-gay identifying MSM, more common in cultures with high levels of stigma about homosexuality, are at higher risk of HIV because of a complex array of factors: in particular, poverty, stigma, drug use and sex work [26]. Male-to-female transgender individuals are particularly stigmatized leading to an increase in risky behavior, including sex work, unprotected sex and needle sharing for the purpose of using illicitly obtained hormones [4, 27].

Despite extensive literature documenting patterns behind the HIV epidemic in Mexico, we have little evidence about gender differences in HIV risk behaviors. The purpose of this study is to describe gender differences in socio-demographic characteristics and risk behaviors of a large, representative population of HIV positive individuals receiving care and treatment in Mexico City. With improved understanding of the differing characteristics, risk factors, and behaviors between men and women in this population, both preventive and treatment services can be tailored to improve outcomes.

\section{Methods}

\section{Data collection}

This study examines cross-sectional data collected at the Clinica Especializada Condesa (CEC) between October 2010 and March 2011 by the National Institute of Public Health of Mexico (INSP). The project was reviewed and approved by INSP Committees of Research, Biosecurity and Ethics (code: 1452895478126086).

The CEC is among the largest outpatient clinics in Latin America specializing in HIV/AIDS. It provides medical care for HIV-positive uninsured Mexicans at no charge. At the end of 2011 it had more than 6,500 active patients and carried out about 5,600 consultations per month. According to CEC estimates, 40,000 people were living with HIV in the city in 2012 (17\% of the national total) and there were roughly 2,800 new infections in 2013 (30\% of all new infections in Mexico) [28].

During the data collection period, all patients in the CEC waiting rooms were invited to participate in this study. Trained INSP personnel explained the study orally and in writing. Oral informed consent was documented, and no record of names was kept of those who did or did not participate, to ensure confidentiality. Following informed consent, participants completed a questionnaire in Spanish using the Audio Computer Assisted Self Interview (ACASI) method. Participants used a touchscreen computer to view and answer questions while also listening to a pre-recorded audio file with the same information.

Individual-level data was collected on socio-demographic background, ethnicity, risk behavior and sexual practices, history of infection, sexual violence, social support [29], self-placement on the social ladder [30], knowledge of HIV, and alcohol and/or drug use at sexual encounters. During the implementation of the survey, study staff was on hand to answer any queries and to provide support to interviewees. Participants could decline to answer any question at any time.

\section{Sample}

In order to have a consistent analytical sample through all the analysis, we excluded participants for whom data was incomplete in any variable of interest. The final analytical sample included 1,490 participants (1,326 men and 164 women), around $85 \%$ of the total sample. 112 men and 155 women were excluded. We found differences between those individuals included in the analysis and those who were excluded. The final analytical sample was characterized by a higher percentage of men, a higher percentage of employed individuals, a lower percentage of people self-identified as gay or lesbian, a higher percentage of people self-identified as heterosexual, and a higher proportion of single people. These differences and their implications on the conclusions will be discussed in the discussion section of the manuscript.

\section{Measurement}

\section{Dependent variables}

We analyzed the following socioeconomic characteristics as dependent variables: marital status (married/cohabiting vs. any other); number of children (having at least 1); 
whether they were living alone at the time of the interview; employment status during the past month; wage (more than the minimal wage vs. less); higher educational level (having completed high school level or higher); lower educational level (6 years or less); and an index of social support based on the Duke's functional questionnaire of perceived social support - previous studies have shown the validity of this questionnaire for the Mexican population [29]. The respondents were classified into two groups: low social support (score between 0 and 31), and high social support (score between 32 and 55 ).

We also analyzed the following sexual behaviors and characteristics as dependent variables: sexual identity (heterosexual vs. gay/lesbian or bisexual); whether the presumed route of HIV infection was by a stable partner; age of first sexual intercourse; and number of sexual encounters in the previous month. Dependent variables related to sexual violence and risk behavior history before HIV diagnosis included: experience in transactional sex (ever); frequency of condom use at sexual encounters (never vs. sometimes, frequently, almost always, always), alcohol or drug use at sexual encounters (never vs. sometimes, frequently, almost always, always); and history of sexual abuse (at least once). Finally, prior migration to the U.S. and prior incarceration were also analyzed as dependent variables.

\section{Control variables}

All models were controlled for the following socioeconomic and risk characteristics: sex, age, indigenous status, living alone, marital status, number of children, educational level, employment status during the past month, prior incarceration, prior migration to the U.S. Sexual identity was included as a control variable in all the models with socioeconomic variables as dependent variables. When any of these control variables was a dependent variable in the model, it was nor included as control.

\section{Other variables included in the descriptive analysis (differences of means)}

In addition to the dependent and control variables described before, the following variables were not included in the regression analyses, but were included in the comparison of means between men and women presented in Tables 1, 2 and 3.

We asked the participants their relative position on the social ladder as they perceive it. The social ladder depicts nine positions and respondents classify themselves with respect to their social environment. We classified their responses in three categories: positions I to III as low, positions IV to VI as middle, and positions VII to IX as high [30]. With respect to history of HIV infection, we analyzed information on the presumed route of HIV infection (blood transfusion, sharing syringes, sex without condom, condom failure), other characteristics of the person who presumably infected the patient (military/police, prisoner, migrant to the USA), and the reason for getting an HIV test (unprotected sex, tested while hospitalized, medical advice, requested by employer). Finally, an additional measure of sexual behavior included was prior sexual experience with men/women only vs. with both men and women.

\section{Analytical strategy}

Descriptive socio-economic and demographic backgrounds as well as the history of HIV infection, and of sexual violence and risk behavior before HIV diagnosis by sex are presented and tested for statistical differences. For categorical variables, chi-square tests were performed to determine statistical independence between men and women in at least one category. Similarly, we used t-tests to determine independence in continuous variables.

Tests for gender differences in a multivariate context were performed modeling the variable sex (male/female) as the primary predictor of marginalization and risk indicators using multivariate, non-linear probability (probit) models. From this models we estimated adjusted probabilities and confidence intervals $[95 \% \mathrm{CI}]$ for two types of outcomes variables:

a. Eight marginalization indicators: marital status (cohabiting or married), having at least one child, living alone, employment status during the previous month, income level (greater than or equal to the minimum wage in Mexico City [31]), level of education (high school or higher and 6 years or less), and perception of high social support.

b. Ten variables related to risk behavior indicators include: sexual identity (heterosexual vs. other), infected by stable partner, age of first sexual intercourse, number of sexual encounters in the previous month, ever engaged in transactional sex, used condom before HIV diagnosis (never vs. at least sometimes), alcohol use before sexual encounters (never vs. at least sometimes), sexual abuse at least once, previous migration to the U.S., and prior incarceration.

The analytical strategy consists on predicting adjusted probabilities of each outcome of interest by sex, while holding all covariates at their mean levels. This strategy was implemented using the margins command in Stata. All analyses were performed using Stata SE 13.1 software [32].

\section{Results}

Of the 1,490 participants, 1,326 (89\%) were men and $164(11 \%)$ women. The average age of 35 years (Table 1$)$, 
Table 1 Socioeconomic and demographic characteristics of study participants

\begin{tabular}{|c|c|c|c|}
\hline \multirow[t]{3}{*}{$N=1,490$} & Women & Men & \multirow[t]{3}{*}{$p$-value* } \\
\hline & $11.2 \%$ & $88.8 \%$ & \\
\hline & \multicolumn{2}{|c|}{ Mean or percentage [Cl-95 \%] } & \\
\hline Age & $35.6[34.0,37.1]$ & $34.8[34.3,35.3]$ & 0.35 \\
\hline \multicolumn{4}{|l|}{ Highest education level } \\
\hline Pre-primary or nothing & $8.38[4.96,13.7]$ & $5.74[4.61,7.14]$ & \multirow[t]{5}{*}{$<0.001$} \\
\hline Primary ( 1 - 6 yrs of schooling) & $29.3[22.9,36.7]$ & $4.54[3.53,5.80]$ & \\
\hline Secondary (7 - 9 yrs of schooling) & $32.3[25.7,39.8]$ & $16.4[14.5,18.5]$ & \\
\hline High school (10 - 12 yrs of schooling) & $14.4[9.80,20.6]$ & $25.7[23.4,28.1]$ & \\
\hline Higher education & $15.6[10.8,21.9]$ & $47.6[44.9,50.3]$ & \\
\hline \multicolumn{4}{|l|}{ Marital status } \\
\hline Single & $32.9[26.2,40.4]$ & $72.3[69.8,74.6]$ & \multirow[t]{4}{*}{$<0.001$} \\
\hline Married/Cohabiting & $41.9[34.7,49.5]$ & $23.7[21.4,26.0]$ & \\
\hline Divorced/Separated & $7.78[4.50,13.0]$ & $3.55[2.67,4.70]$ & \\
\hline Widow or widower & $17.4[12.3,23.9]$ & $0.53[0.23,1.11]$ & \\
\hline Partner died of AIDS (among widows or widowers) & $85.2[66.9,94.7]$ & $85.7[46.7,99.5]$ & 0.97 \\
\hline \multicolumn{4}{|l|}{ Number of children } \\
\hline 0 & $18.0[12.8,24.5]$ & $87.6[85.7,89.3]$ & \multirow[t]{4}{*}{$<0.001$} \\
\hline 1 & $26.9[20.8,34.2]$ & $4.84[3.80,6.14]$ & \\
\hline 2 & $23.4[17.6,30.4]$ & $4.31[3.33,5.55]$ & \\
\hline 3 or more & $31.7[25.1,39.2]$ & $3.25[2.41,4.36]$ & \\
\hline Indigenous & $11.4[7.38,17.3]$ & $7.48[6.17,9.04]$ & 0.08 \\
\hline Living alone & $5.39[2.72,10.1]$ & $19.0[16.9,21.2]$ & $<0.001$ \\
\hline Worked the past month & $67.1[59.6,73.8]$ & $75.7[73.4,78.0]$ & 0.02 \\
\hline \multicolumn{4}{|l|}{ Type of contract } \\
\hline Temporary & $14.0[8.72,21.7]$ & $21.6[19.1,24.3]$ & \multirow[t]{3}{*}{$<0.001$} \\
\hline Permanent & $7.02[3.41,13.4]$ & $17.4[15.2,19.9]$ & \\
\hline None & $78.9[70.5,85.5]$ & $61.0[57.9,64.0]$ & \\
\hline Wage [mean, sd] in US\$ & $172.1[150.6,193.5]$ & $391.8[366.3,417.2]$ & $<0.001$ \\
\hline \multicolumn{4}{|l|}{ Duke-UNK's Social Support classification } \\
\hline High social support & $62.1[53.6,69.9]$ & $72.0[69.2,74.6]$ & 0.03 \\
\hline \multicolumn{4}{|l|}{ Self-placement on the social ladder } \\
\hline | to ||| & $15.3[8.01,26.7]$ & $5.07[3.30,7.67]$ & \multirow[t]{3}{*}{$<0.001$} \\
\hline IV to VI & $39.0[27.6,51.8]$ & $21.3[17.6,25.5]$ & \\
\hline VII to IX & $45.8[33.7,58.3]$ & $73.7[69.2,77.7]$ & \\
\hline Previously in prison & $2.53[0.77,6.55]$ & $4.68[3.64,5.98]$ & 0.22 \\
\hline Previously migrated to the USA & $2.55[0.77,6.59]$ & $11.8[10.2,13.7]$ & $<0.001$ \\
\hline \multicolumn{4}{|l|}{ Sexual identity } \\
\hline Gay/Lesbian & $1.20[0.05,4.54]$ & $80.3[78.0,82.3]$ & \multirow[t]{3}{*}{$<0.001$} \\
\hline Heterosexual & $91.0[85.6,94.6]$ & $11.0[9.45,12.8]$ & \\
\hline Bisexual & $7.78[4.50,13.0]$ & $8.69[7.29,10.3]$ & \\
\hline
\end{tabular}

Footnote: * Tests for differences in means or proportions. We used bivariate $t$-test for continuous variables and Chi-square test for categorical variables to compare men and women

and the male:female ratio was $8: 1$, which is consistent with the total population of the CEC $(7.7: 1)$ at the time of the survey.
In bivariate analyses (Table 1), we found several statistically significant differences $(p<0.05)$ between men and women. Seventy-three percent of men had 10 or more 
Table 2 History of HIV infection among study participants

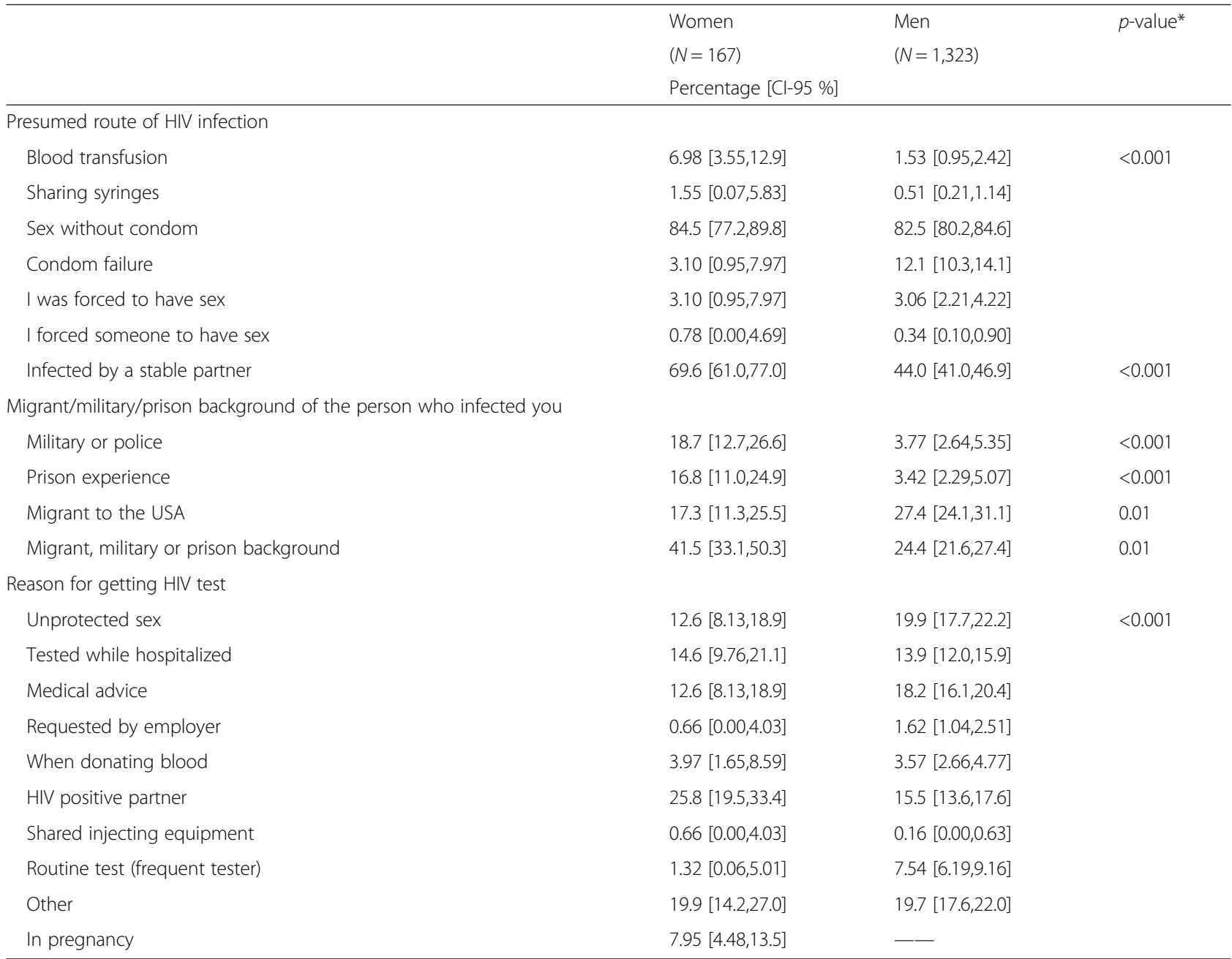

Footnote: *Tests for differences in means or proportions. We used bivariate $t$-test for continuous variables and Chi-square test for categorical variables to compare men and women

years of schooling compared with $30 \%$ of women; $72 \%$ of men were single, compared with $33 \%$ of women. While $88 \%$ of men were childless, only $18 \%$ of women reported not having children. Speaking an indigenous language (a commonly used proxy for extreme social vulnerability in Mexico) was more common among women than men. Living alone was more common among men than women.

Further differences were found in terms of labor and social placement outcomes. First, $75 \%$ of men indicated having worked during the past month, and among them an average monthly salary of US\$392 was reported. In comparison, $67 \%$ women worked during the past month, with an average monthly salary of US $\$ 172$. On the other hand, $72 \%$ of men perceived having high social support vs. $62 \%$ of women, and $74 \%$ of men placed themselves between tiers VII and IX of the social ladder vs. $46 \%$ of women.
In terms of contextual and sexual risk factors we found that previous migration to the USA was significantly higher among men than women. In terms of sexual identity, $80 \%$ of men reported being homosexual vs. $91 \%$ of women reported being heterosexual.

Table 2 displays crude differences related to selfreported HIV history. We found no significant gender difference in unprotected sex as the presumed mechanism of infection. However, women were significantly more likely to have been infected via blood transfusion or sharing syringes and less likely to have been infected due to condom failure ( $3.1 \%$ vs. $12.1 \%$ ). Significant statistical differences were found in other characteristics within this dimension: women were significantly more likely to have been infected by a stable partner, by a partner with military/police background or imprisonment background, though less likely by a partner with a history of migration to the U.S. Women were more likely to have 
Table 3 Sexual violence and risk behaviour history before HIV diagnosis among study participants

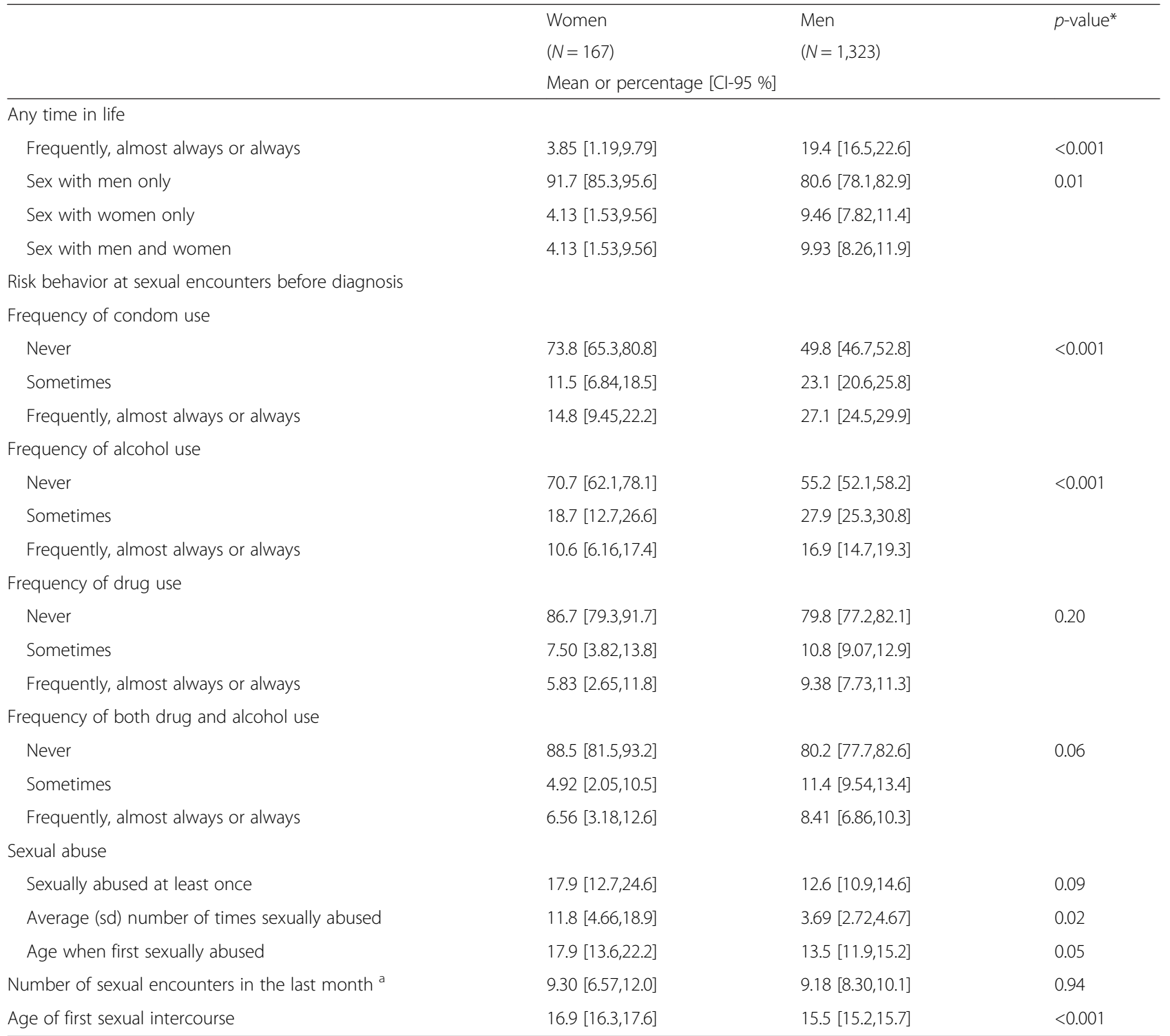

Footnote: *Tests for differences in means or proportions. We used bivariate $t$-test for continuous variables and Chi-square test for categorical variables to compare men and women

${ }^{\mathrm{a}} 78 \%$ of women reported having frequent sex with regular partners ( $42.9 \%$ among males), the rest reported frequent sex with an occasional or one-time partner (data not shown)

been tested because they found out that their partner was HIV positive, and only $8 \%$ were diagnosed during pregnancy.

Furthermore, in Table 3 we explore crude differences in terms of sexual behavior and other HIV risk factors before their HIV diagnosis. Men were significantly more involved in transactional sex than women: $19.4 \%$ of men vs. $3.9 \%$ women had paid or received money for sex; and among men, $90.5 \%$ reported that the transaction involved other men. Condom use was less frequent among women. Women were less likely to use alcohol at sexual encounters. Additionally, no differences in percentage of sexual abuse; however women reported more occurrences of it. Mean age at first abuse was younger for men. No difference in the average of sexual encounters in the last month was identified.

In Figs. 1 and 2 we show the results of the second part of the analysis. We estimated adjusted probabilities of occurrence of selected socioeconomic characteristics, sexual behaviors and other HIV-related risk characteristics, by sex. Our results show that while the HIV epidemic among men is linked mainly to sexual risk behavior, the epidemic among women is mainly linked to social and economic vulnerability and marginalization.

First, we show that adjusting for other demographic, socioeconomic and sexual identity characteristics, HIV- 


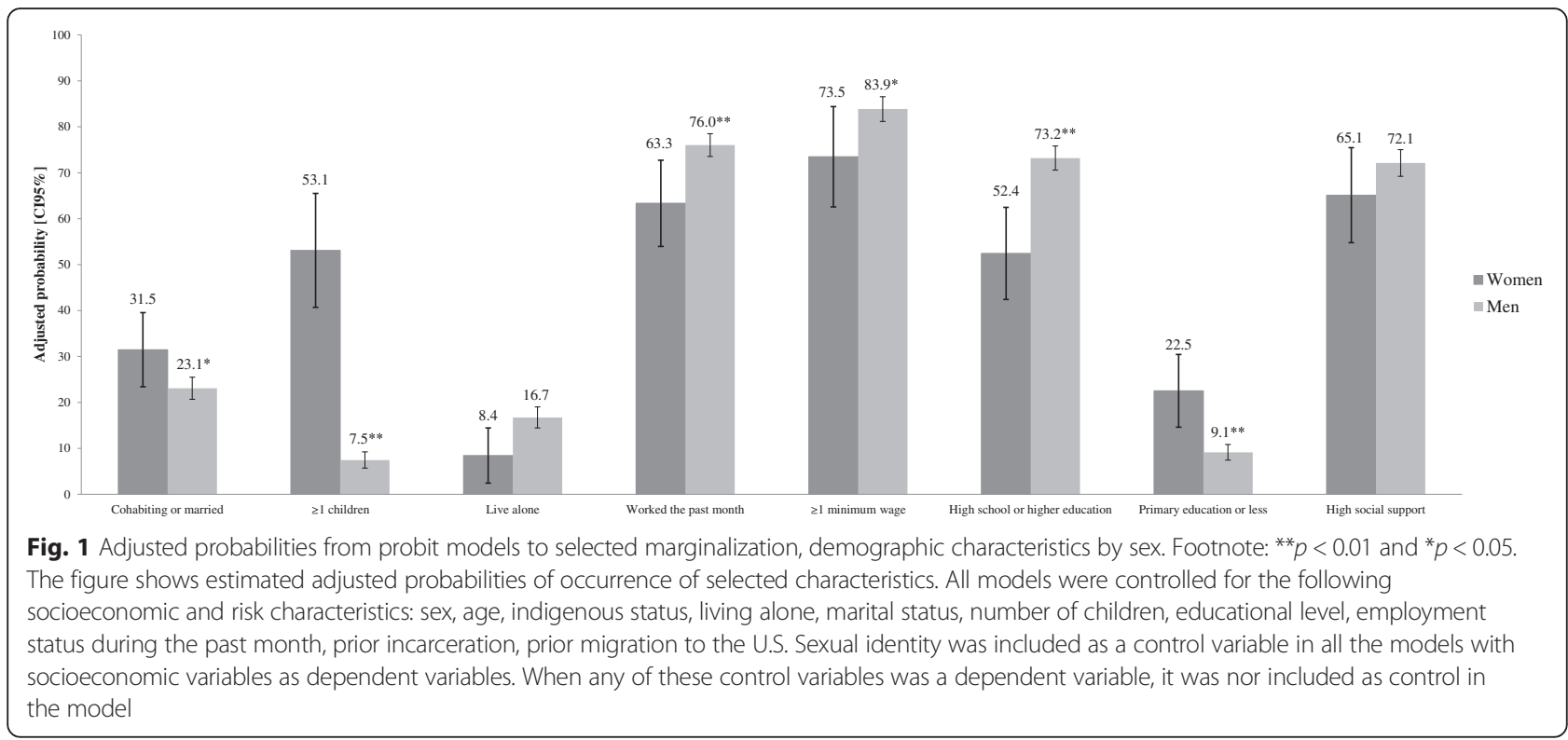

infected women are more likely to be married or living with a stable partner, and more likely to have children. Similarly, HIV-infected women have a lower probability of having been employed in the past month than men; and among those employed, women are less likely to earn more than the minimal wage than men. At the same time, HIV-positive women are significantly more likely to have primary or lower level of education, and less likely to have high school or higher level of education than men.

The picture is completed in Fig. 2, where we present the adjusted probabilities of sexual and other HIVrelated risk characteristics. Women are significantly more likely to report being heterosexual than men and also more likely to report being infected by a stable partner. Men report a younger age of first sexual intercourse. The likelihood of having been engaged in transactional sex is significantly higher for men than for women. Women were more likely to never have used condoms before HIV diagnosis and more likely to never have used alcohol at sexual encounters before diagnosis. The adjusted probability of having been sexually abused is significantly higher for women than for men. Men were more likely to have previous experience of both migration to the U.S., and imprisonment than women.

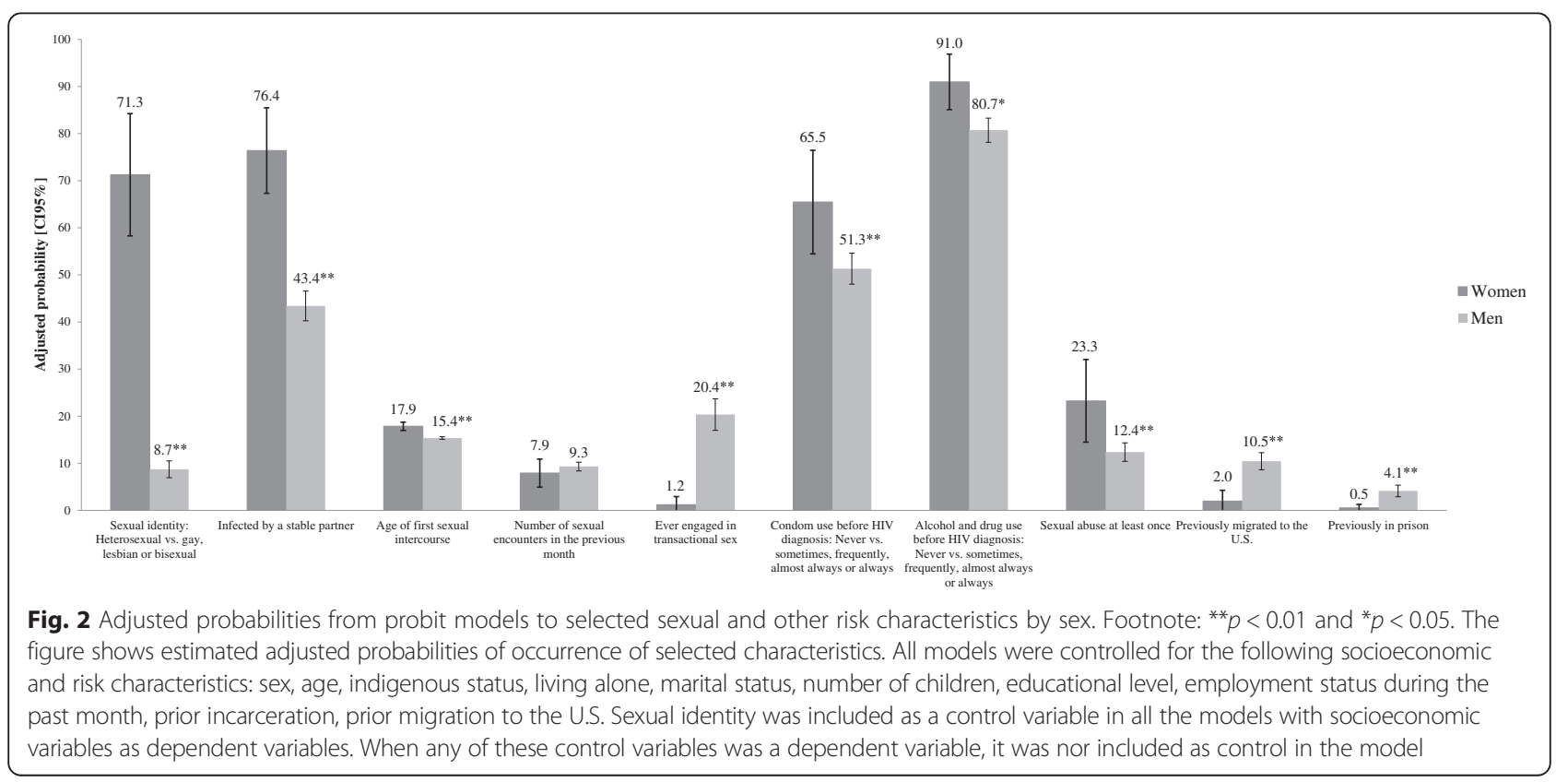




\section{Discussion}

Our results highlight the key structural differences between HIV-positive men and women in Mexico City. Our results are consistent with the hypothesis that the HIV epidemic in Mexico is not one, but two different epidemics: one linked to sexual risk behavior among MSM with relatively high levels of education and low levels of poverty, and a different one among women explained by social vulnerability and economic marginalization. Women in this study are particularly vulnerable in socio-economic terms, while men demonstrate riskier behaviors. Women were more likely to have children, which, in combination with lower levels of formal employment, salary, and lower self-placement on the social ladder points to significant socio-economic vulnerability for both the women and their children.

To our knowledge, this is the first study on gender differences among HIV/AIDS patients in large urban settings in Mexico. Although there is large body of literature addressing these aspects among sex workers, injecting drug users and their partners, and partners of migrants in rural communities, almost no study has been published on women from the "general population" and their risk to get infected with HIV in Mexico. This topic has been well documented in the US with comparable results, more prominently through the body of research recently described as the "vulnerability paradigm" [31] which described the vulnerable position of women towards HIV infection compared with men, as a result of biological differences in susceptibility, sexual autonomy and power dynamics between men and women [33-37].

The study was based in an HIV clinic for the uninsured population, which includes the roughly $50 \%$ of the population with lower socioeconomic status in Mexico. However, while male participants had salaries only marginally less the national average (US\$411/month, [38]), women's average salary was less than half of men's. The proportion of participants who speak an indigenous language (7.38 \%) is five times higher than that of Mexico City's general population [39], and for women it is almost eight times higher, highlighting the even greater vulnerability of indigenous women who migrated to the national capital.

Women in rural communities have been found to be particularly vulnerable due to unprotected sex with stable partners, citing many reasons for not negotiating condom use [14]. Women in Mexico City may face the same problem - female participants were significantly less likely to use condoms and had a greater (self-reported) probability of acquiring HIV from a stable partner, which may reflect their difficulty negotiating condom use in stable relationships.

Female participant's vulnerability is further demonstrated by the greater amount of sexual abuse they have suffered. IPV is a known factor in women's vulnerability to HIV $[8,16]$ and though not all forms of IPV were assessed, women reported that the perpetrator of sexual abuse was more likely to have been a partner, or someone well-known to them. Furthermore, they were more vulnerable to infection by military/police men, or former prisoners. Previous studies have found high levels of unprotected sex with other men among the male partners of HIV positive women [9]. The risk behaviors of male partners of women in the study were not assessed, but $7 \%$ of male participants reported having sex with men and women. A previous study of MSM in Mexico found that $17.6 \%$ self-identified as bisexual and $41 \%$ reported previous sex with women $[7,10]$.

MSM are known to be at greater risk of HIV for several reasons [9]. Almost $90 \%$ of men in this study were MSM, and despite more consistent condom use than women, $50 \%$ reported never using condoms before diagnosis, a substantial risk for MSM, the group among which HIV prevalence is highest in Mexico. Men demonstrated higher risk behavior in reporting greater involvement in transactional sex. Migration, another known factor in increasing risk behavior [11], was more commonly reported by men than women - both in terms of personal history and of the person who they reported to have infected them.

The study was limited by its cross-sectional design, allowing for only statistical associations rather than causal inferences to be made, and by the fact that all behaviors were self-reported. Our results may thus be subject to bias and measurement error, particularly in relation to the source of infection. A larger percentage of women were excluded from the study due to missing data. The reason for this is unknown, but anecdotal information from the field during data collection suggests that it may reflect increased time pressure for women and the feeling of decreased ability to complete the questionnaire due to higher illiteracy, impacting women's ability to complete the survey, which may have excluded some of the most vulnerable women, thus potentially biasing downwards the difference between men and women found in the analysis. This implies that our results are likely a conservative estimation of the social vulnerability of women in this study.

Though the information was treated as confidential, characteristics such as drug use and sex work may have been under-reported due to fear of legal implications. Information on experience of sexual violence may also be under-reported due to its distressing nature. However, we do not expect that these possible biases would be systematically different between men and women.

Despite these limitations, this study has shed light on differences by gender in the HIV epidemic in Mexico City and suggests that there are two epidemics in 
Mexico, pointing to the vulnerability of women and the risky sexual behavior of men. Identifying factors contributing to both vulnerability and risk will help guide both prevention and treatment efforts. MSM are particularly at risk, and prevention strategies should continue to target this group, focusing on risk reduction, particularly greater use of condoms and HIV testing for earlier diagnosis and linkage to care and treatment. Sex workers and migrants appear to be particularly important subpopulations in prevention strategies.

The strategies to address the epidemic among women need to be different. Universal HIV testing for pregnant women and easy access to testing for all other women should probably be a central component of the strategy. Additionally, finding effective ways to increase awareness among women of the risk of HIV and higher access to preventive methods such as condoms and HIV testing for those without a stable partner, should also be a priority. Perhaps more importantly, there is an urgent need to encourage men living with HIV to disclose to their partners, and to encourage couples testing, however there is no evidence on how to effectively do it. Researchers and policy makers need to find ways to do this respecting human rights of people living with HIV but also placing women's health as a high priority.

Additionally, it is important to change the perception of the healthcare community in Mexico of virtually no risk for HIV infection among women. There must be concerted efforts to encourage testing for victims of sexual abuse. A higher attention should be given to women in higher risk groups such as those with partners having sex with men and women and partners with a military, police or prison background. Early counseling to encourage disclosure by men living with HIV with female partners should be encouraged [40]. Long-term follow-up should be arranged for sero-discordant couples to provide access to regular screening, counseling and condoms and for sero-concordant couples for monitoring of their sexual and reproductive health needs.

Those providing treatment also need to recognize the socio-economic vulnerability of women and their children. Poverty plays an important role for both sexes but women in the study were significantly more affected.

\section{Conclusion}

Significant differences exist between men and women with HIV in Mexico City. Women live in a context of high social and economic vulnerability; while men are characterized by riskier sexual behavior. Therefore, the strategies to address the epidemic among women need to be different than those typically implemented in Mexico and other countries with concentrated epidemics. More complex interventions targeting other determinants beyond sexual behavior are needed. Strategies should pay particular attention to the most vulnerable women and include the provision of information and services in indigenous languages if needed. Furthermore, our results suggest that other structural components must be considered as well and that prevention of HIV is yet another reason to improve women's access to education on reproductive rights, on sexual and reproductive health, and to increase access to economic opportunities and improved living conditions.

However, because both sexes face significant socioeconomic disadvantage and stigma, gender issues must be addressed in both prevention and treatment efforts, focusing on equality at work and home, and ensuring access to social protection services. Future strategies to increase awareness, diagnosis and treatment should take this into account in order to try and maximize impact, and monitoring and evaluation should be carried out with attention to gender specific differences.

\section{Competing interests}

The authors declare that they have no competing interests.

\section{Authors' contributions}

SBA designed the study and survey instruments. SBA and ESM outlined the idea for the paper and wrote the first draft of the manuscript. ESM and FB analyzed the data. AG and PV substantially revised the drafts. All authors were involved revising the final version of the manuscript. All authors read and approved the final manuscript.

\section{Acknowledgments}

This work was possible with the support of the Institute of Science and Technology of Mexico City (ICyT). We thankfully acknowledge the continuous support from Mexico City's AIDS program and the generous help from the staff of the Clinica Especializada Condesa (CEC). Finally, we thank the study participants for their contribution to the study.

\section{Author details}

${ }^{1}$ National Institute of Public Health, Cuernavaca, Mexico. ${ }^{2}$ Mexico City's AIDS Program, Mexico City, Mexico. ${ }^{3}$ National Institute of Oncology, Mexico City, Mexico.

Received: 15 April 2015 Accepted: 11 December 2015

Published online: 16 December 2015

\section{References}

1. Bautista-Arredondo S, Colchero MA, Romero M, Conde-Glez CJ, Sosa-Rubí SG. Is the HIV epidemic stable among MSM in Mexico? HIV Prevalence and risk behavior results from a nationally representative survey among men who have sex with men. PLoS One. 2013;8(9):e72616. doi:10.1371/ journal.pone.0072616.

2. Centro Nacional para la Prevención y Control de SIDA (CENSIDA). EI VIH/ SIDA en Mexico 2009. Available from: http://www.censida.salud.gob.mx/ descargas/2009/NIHSIDAenMexico2009.pdf.

3. Centro Nacional para la Prevención y Control del VIH/SIDA (CENSIDA). Informre nacional sobre los progresos realizados en la aplicación de UNGASS. México 2010. Available from:http://www.censida.salud.gob.mx/ descargas/ungass/InformeUNGASS_2010/INFORME_UNGASS_MEX_2010.pdf.

4. Colchero MA, Cortés-Ortiz MA, Romero-Martínez M, Vega H, González A, Román R, et al. HIV prevalence, sociodemographic characteristics, and sexual behaviors among transwomen in Mexico City. Salud Publica Mex. 2015;57:s99-s106.

5. Bautista-Arredondo S, González A, Servan-Mori E, Beynon F, Juarez-Figueroa L, et al. A cross-sectional study of prisoners in Mexico City comparing prevalence of transmissible infections and chronic diseases with that in the general population. PLoS One. 2015;10(7):e0131718. doi:10.1371/journal.pone.0131718. 
6. Cahuana-Hurtado L, Chilian-Herrera O, Bautista-Arredondo S, Contreras-Loya D, Franco-Marina F, González-Vilchis JJ, et al. Corrección de la mala clasificación de las muertes por SIDA en México. Análisis retrospectivo de 1983 a 2012. Salud Pública Mex. 2015;57:s142-s152. Recuperado en 12 de diciembre de 2015, dehttp://www.scielo.org.mx/scielo.php?script=sci_arttext\&pid=S003636342015000800008\&lng=es\&tlng=es

7. Pan-American Health Organization (PAHO). The UNGASS, Gender and Women's Vulnerability to HIV/AIDS in Latin America and the Caribbean. Women, Health and Development Program. Washington DC; 2002. Available from: http://hivhealthclearinghouse.unesco.org/library/documents/ungassgender-and-womensvulnerability-hivaids-latin-america-and-caribbean.

8. Hirsch JS, Meneses S, Thompson B, Negroni M, Pelcastre B, del Rio C. The inevitability of infidelity: sexual reputation, social geographies, and marital HIV risk in rural Mexico. Am J Public Health [Internet]. 2007 Jun [cited 2011 Oct 3]; 97(6):986-96. Available from: http://www.pubmedcentral.nih.gov/ articlerender.fcgi?artid=1874214\&tool=pmcentrez\&rendertype=abstract .

9. Magis-Rodríguez C, Bravo-García E, Gayet-Serrano C, Rivera-Reyes P, De Luca M. El VIH y el SIDA en México al 2008: Hallazgos, tendencias y reflexiones. 2008. Available from: http://www.censida.salud.gob.mx/descargas/ biblioteca/NIHSIDA_MEX2008.pdf.

10. Gayet C, Magis-Rodriguez C, Sacknoff D, Fernandez A, Guli L, RamírezAranda J, et al. High prevalence of HIV and limited use of condoms among MSM: results from a biological and behavioral surveillance in Mexican urban contexts. AIDS 2006 - XVI International AIDS Conference Abstract no. MOPE0480. Avaiulable from: https://www.aids2014.org/Abstracts/A2192474. aspx.

11. Magis-Rodríguez C, Gayet C, Negroni M, Leyva R, Bravo-García E, Uribe P, et al. Migration and AIDS in Mexico: an overview based on recent evidence. J Acquir Immune Defic Syndr [Internet]. 2004 Nov 1;37 Suppl 4:S215-26. Available from: http://www.ncbi.nlm.nih.gov/pubmed/15722864.

12. Goldenberg SM, Strathdee S a, Perez-Rosales MD, Sued O. Mobility and HIV in central America and Mexico: a critical review. J Immigrant Minority Health/Center Minority Public Health [Internet] 2012 Feb [cited 2012 Feb 29];14(1):48-64. Available from: http://www.ncbi.nlm.nih.gov/pubmed/ 21789558.

13. Caballero Hoyos R, Torres Lopez T, Pineda Lucatero A, Navarro Nuñez C, Fosados R, Valente TW. Between tradition and change: condom use with primary sexual partners among Mexican migrants. AIDS Behav [Internet] 2008;12(4):561-9. Available from: http://www.ncbi.n/m.nih.gov/pubmed/ 18389360.

14. Hirsch JS, Higgins J, Bentley ME, Nathanson C. a. The social constructions of sexuality: marital infidelity and sexually transmitted disease-HIV risk in a Mexican migrant community. Am J Public Health [Internet]. 2002;92(8):1227-37. Available from: http://www.pubmedcentral.nih.gov/articlerender. fcgi?artid=1447220\&tool=pmcentrez\&rendertype=abstract.

15. Carol S, Jose LS, Licea Al, Rangel MG, Martínez-donate AP, Hovell MF. Prevalence of risk factors for HIV infection among Mexican migrants and immigrants : Probability survey in the North border of Mexico. Health (San Francisco). 2006:48:3-12.

16. Silverman JG, Decker MR, Saggurti N, Balaiah D, Raj A. Intimate partner violence and HIV infection among married Indian women. JAMA J Am Med Assoc [Internet]. 2008;300(6):703-10. Available from: http://www.ncbi.nlm. nih.gov/pubmed/18698068.

17. Tsai AC, Subramanian SV. Proximate context of gender-unequal norms and women's HIV risk in sub-Saharan Africa. AIDS [Internet]. 2012;26(3):381-6. Available from: http://www.ncbi.nlm.nih.gov/pubmed/22045344.

18. Decker MR, Seage GR, Hemenway D, Gupta J, Raj A, Silverman JG. Intimate partner violence perpetration, standard and gendered STI/HIV risk behaviour, and STI/HIV diagnosis among a clinic-based sample of men. Sexually Transmitt Infect [Internet]. 2009:85(7):555-60. Available from: http://www.ncbi.nlm.nih.gov/pubmed/19625287.

19. Kayibanda JF, Bitera R, Alary M. Violence Toward Women, Men's Sexual Risk Factors, and HIV Infection Among Women: Findings From a National Household Survey in Rwanda. J Acquired Immune Deficiency Syndromes (1999) [Internet]. 2012;59(3):300-7. Available from: http://www.ncbi.nlm.nih. gov/pubmed/22227491.

20. Instituto Nacional de Estadística y Geografía (INEGI). Mujeres violentadas por su pareja en México. 2007. Available from:http://www.inegi.org.mx/prod_ serv/contenidos/espanol/bvinegi/productos/estudios/sociodemografico/ mujeresrural/muj_viol.pdf.
21. Cáceres CF, Aggleton P, Galea JT. Sexual diversity, social inclusion and HIV/ AIDS. AIDS (London, England) [Internet]. 2008;22 Suppl 2:S45-55. Available from: http://www.ncbi.nlm.nih.gov/pubmed/18641469.

22. Iko Safika, Timothy P. Johnson, Young Ik Cho, and Ignatius Praptoraharjo. Condom Use Among Men Who Have Sex With Men and Male-to-Female Transgenders in Jakarta, Indonesia Am J Mens Health 1557988313508430, first published on November 7, 2013 doi:10.1177/1557988313508430.

23. Chow EP, Wilson DP, Zhang L. Patterns of condom use among men who have sex with men in China: a systematic review and meta-analysis. AIDS Behav. 2012;16(3):653-63. doi:10.1007/s10461-011-9935-9.

24. Ramanathan S, Chakrapani V, Ramakrishnan L, Goswami P, Yadav D, et al. Consistent condom use with regular, paying, and casual male partners and associated factors among men who have sex with men in Tamil Nadu, India: findings from an assessment of a large-scale HIV prevention program. BMC Public Health. 2013;13:827. doi:10.1186/1471-2458-13-827.

25. Glick SN, Morris M, Foxman B, Aral SO, Manhart LE, Holmes KK, et al. A comparison of sexual behavior patterns among men who have sex with men and heterosexual men and women. JAIDS J Acquired Immune Deficiency Syndromes [Internet]. 2012 Jan [cited 2012 Mar 7]:1. Available from: http://www.ncbi.nlm.nih.gov/pubmed/22522237.

26. Finlinson HA, Colón HM, Robles RR, Soto M. Sexual identity formation and AIDS prevention: an exploratory study of non-gay-identified Puerto Rican MSM from working class neighborhoods. AIDS Behav [Internet]. 2006;10(5):531-9. Available from: http://www.macses.ucsf.edu/research/psychosocial/subjective. php.

27. Crosby R, Pitts N. Caught between different worlds: how transgendered women may be "forced" into risky sex. J Sex Res. 2007:44(1):43-8.

28. Clinica Especializada Condesa (CEC): http://condesadf.mx/distrito-federal. htm. Accessed 20 Aug 2015

29. Bellón JA, Delgado A, Luna Del Castillo JD, Lardelli R. Validez y habilidad del cuestionario de apoyo social funcional Duke-UNC-11. Aten Primaria. 1996;18:153-63.

30. Adler N, Stewart J: The MacArthur Scale of Subjective Social Status. 2007. http://www.macses.ucsf.edu.

31. Higgins JA, Hoffman S, Dworkin SL. Rethinking Gender, Heterosexual Men, and Women's Vulnerability to HIV/AIDS. Am J Public Health. 2010;100(3):435-45. doi:10.2105/AJPH.2009.159723.

32. Stata Corp. LP. Stata/SE 12.1 for Windows XP 64 bits. College Station Texas, USA: Stata Corp LP; 2011.

33. Wenzel SL, Tucker JS. Reemphasizing the context of women's risk for HIV/AIDS in the United States. Womens Health Issues. 2005;15(4):154-6.

34. Ojikutu BO, Stone VE. Women, inequality, and the burden of HIV. N Engl J Med. 2005;352(7):649-52.

35. Joint United Nations Programme on HIV/AIDS. UN Population Fund, UN Development Fund for Women and HIV/AIDS: Confronting the Crisis New York. NY: UN Population Fund; 2004.

36. Gupta GR. How men's power over women fuels the HIV epidemic. BMJ. 2002:324(7331):183-4.

37. Krishnan S, Dunbar MS, Minnis AM, Medlin CA, Gerdts CE, Padian NS. Poverty, gender inequities, and women's risk of human immunodeficiency virus/AIDS. Ann N Y Acad Sci. 2008;1136:101-10.

38. INEGI. Presentation: Encuesta de Ingresos y Gastos de los Hogares-ENIGH 2010 [Internet]. 2011. Available from: http://www.inegi.org.mx/est/contenidos/ Proyectos/Encuestas/Hogares/regulares/Enigh/Enigh2010/tradicional/.

39. INEGI. Presentation: Principales resultados del Censo de Población y Vivienda 2010 [Internet]. 2011. Available from: http://www.inegi.org.mx/est/ contenidos/proyectos/ccpv/cpv2010/Default.aspx.

40. Cohen MS, Chen YQ, McCauley M, Gamble T, Hosseinipour MC, Kumarasamy $\mathrm{N}$, et al. Prevention of HIV-1 infection with early antiretroviral therapy. N Engl J Med. 2011;365(6):493-505. 